\title{
Polymyxin B Attenuates LPS-Induced Death but Aggravates Radiation-Induced Death via TLR4-Myd88-IL-6 Pathway
}

\author{
Ying Cheng ${ }^{\mathrm{a}}$ Jicong Du Jiaqi Han ${ }^{\mathrm{a}}$ Weimin Sun ${ }^{\mathrm{b}} \quad \mathrm{Fu} \mathrm{Gao^{ \textrm {a } }}$ Pei Zhang ${ }^{\mathrm{a}}$ \\ Hainan Zhao ${ }^{a}$ Ming Chen ${ }^{a}$ Jianing Wanga Mingyu Wanga Suhe Donga \\ Ding Sun ${ }^{a}$ Yandong Zhang ${ }^{c}$ Jianguo Cui ${ }^{\mathrm{a}}$ Jianming Cai ${ }^{\mathrm{a}}$ Cong Liu ${ }^{\mathrm{a}}$
}

${ }^{a}$ Department of Radiation Medicine, Faculty of Naval Medicine, ${ }^{b}$ National Key Laboratory of Medical Immunology \& Institute of Immunology, Second Military Medical University, Shanghai, cModel Animal Research Center, Nanjing University, Nanjing, China

\section{Key Words}

Polymyxin B • LPS • Radiation • TLR4 • Myd88 • IL-6

\begin{abstract}
Background/Aims: Polymyxin B (PMB) is a cyclic cationic polypeptide antibiotic widely used to counteract the effects of endotoxin contamination, both in vitro and in vivo. Lipopolysaccharide (LPS) is an endotoxin that acts as a radiation protection factor. In this study, we focus on the role of PMB in LPS-induced and radiation-induced mortality in mice. Methods: Mice received total-body radiation or were pretreated by LPS or PMB, and the survival of mice was recorded. Elisa were used to detect the cytokines levels. Results: PMB decreased LPS-induced, but increased radiation-induced mortality in mice. Moreover, PMB could block the LPS-induced radioprotective effect. The ELISA and gene knock-out experiments indicated that PMB reduces TNF- $\alpha$ level to block LPS-induced mortality in mice, and inhibits IL-6, G-CSF and IL-10 to increase radiation-induced mortality via the TLR4-Myd88-IL-6 pathway. Conclusions: Our study revealed a role of PMB in LPS-induced endotoxemia and radiation exposure. We infer that the TLR4-Myd88-IL-6 pathway may play a crucial role in the process.

\section{Introduction}

High dose radiation leads injuries of hematopoietic system (HP) and gastrointestinal tract have been well confirmed. However, the involved molecular mechanisms are still unclear.

Toll-like receptors (TLRs) play the key roles in the innate immune response [1-7]. In our previous studies, we have proved that TLR2 and TLR4 play critical roles in radio-resistance.

Y. Cheng, J. Du and J. Han contributed equally to this work.

Jianming Cai and Cong Liu Department of Radiation Medicine, Second Military Medical University; 800, Xiangyin 
Injection of lipopolysaccharide (LPS) or TLR2 agonist Pam3CSK4 into wild type mice will activate TLR4 or TLR2 in vivo and induced radio-resistance separately [8, 9].

Polymyxin B (PMB) is a cyclic cationic polypeptide antibiotic produced by soil bacterium Paenibacillus polymixa [10-14]. PMB is widely used to eliminate the effects of endotoxin contamination, both in vitro and in vivo. The involved mechanism is that PMB is the TLR signaling inhibitor and could block the biological effects of LPS through binding to lipid A, the toxic component of LPS, which is negatively charged [15-17]. Moreover, the neutralizing effect of PMB on LPS is dose-related and specific for LPS [18].

We have investigated the importance of TLR signal pathway in radiation resistance for years. In this study, PMB, the inhibitor of TLR signaling, was applied to investigate TLR in radiation resistance.

\section{Materials and Methods}

Reagent

Polymyxin B (Catalog \#tlrl-pmb) was purchased from InvivoGen (San Diego, CA, USA) and was stored at $4^{\circ} \mathrm{C}$. LPS from Escherichia coli was purchased from Sigma (Saint Louis, MO, USA).

\section{Total body Radiation}

Mice received total-body radiation at the radiation center in the faculty of Naval Medicine, Second Military Medical University, China [19, 20], and the survival of mice was recorded.

Mice

Adult wild type mice and TLR $4 \%$, Myd88 $\%$ and IL-6 $\%$ mice were purchase from the Model Animal Research Center of Nanjing University (Nanjing, China) as described previously [21].

ELISA

The IL-6, TNF- $\alpha$, G-CSF and IL-10 level in the serum of mice were analyzed by ELISA kits as previously described [19]. The ELISA kit was purchased from Jianglai-bio com (Jianglai, Shanghai, China).

Statistical analysis

A two-tailed Student's t test was used to analyze the differences between the two groups. ANOVA was used to analyze the difference of three groups. The Kaplan-Meier analysis was used to evaluate the overall survival of treated mice as previously described [19]. All statistical analyses were performed using SPSS Version 19 (IBM Corp., Armonk, NY, USA).

\section{Results}

PMB decreased LPS induced mice mortalities but increased radiation induced mice mortalities

Our previous study proved that LPS was radioprotective in mice [9], and PMB is an inhibitor of TLR signaling. Accordingly, we first evaluated the effect of PMB on the survival of LPS-treated and radiation-treated mice. Groups of mice were pretreated with either PMB ( $50 \mathrm{\mu g} /$ mouse) for 24 hours before treatment with either LPS ( 1 and $2 \mathrm{mg} / \mathrm{mouse}$ ) or totalbody radiation (IR) ( 7 and 9 Gy). Mice were then monitored daily for survival. We found that the mice survival rate went down to zero in three days after LPS treatment without the PMB pretreatment (Fig. 1A/B), while those pretreated with PMB survived longer. Meanwhile, radiation-treated mice were observed for 30 days and we found that mice pretreated with PMB had lower survival rates in both the 7 and 9 Gy groups (Fig. 1C/D). Overall, primarily 
A

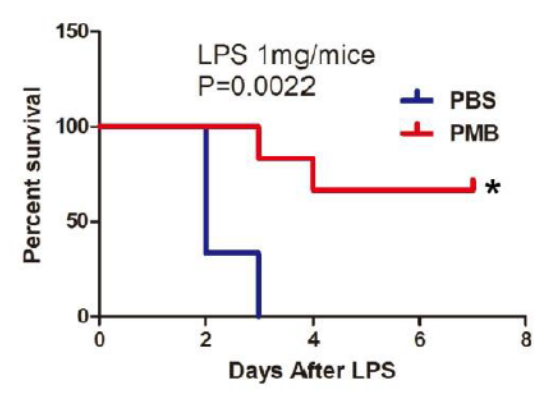

C

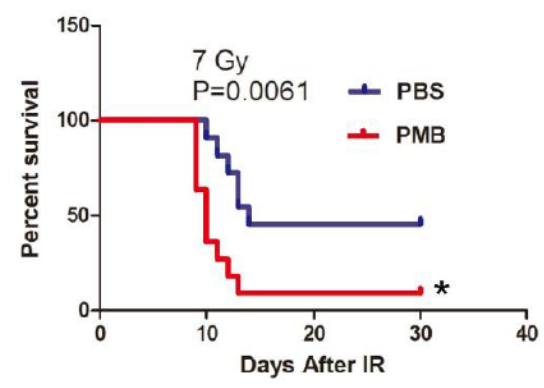

B

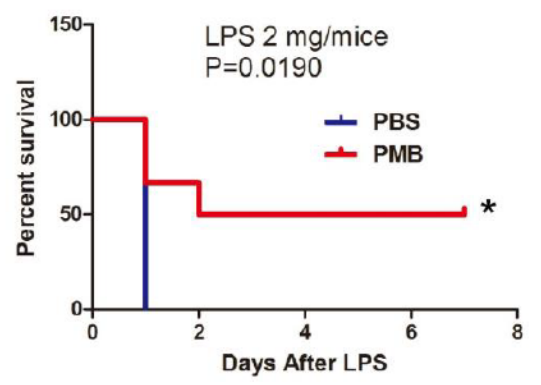

D

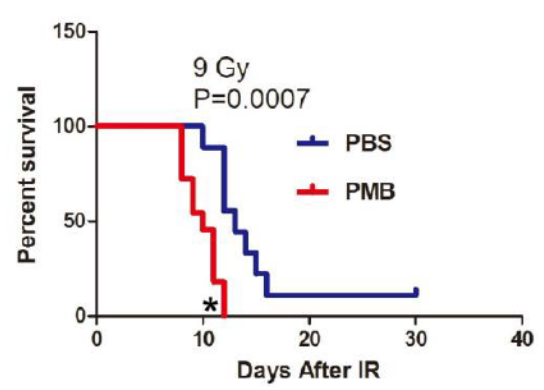

Fig. 1. PMB decreased LPS-induced mortality but increased radiation-induced mortality in mice. PMB (100 $\mu \mathrm{g} / \mathrm{mouse}$ ) was injected into each mouse via the caudal vein, 30 minutes later, LPS (1 or $2 \mathrm{mg} / \mathrm{mouse}$ ) was injected via the caudal vein into each mouse. Mice were monitored daily for survival and the survival rates were calculated (A/B). PMB (100 $\mu \mathrm{g} /$ mouse) was injected into each mouse via the caudal vein, 30 minutes later, each mouse received 7 Gy or 9 Gy total-body radiation. Mice were monitored daily for survival and the survival rates were calculated (C/D). Differences in survival between the two groups of mice were evaluated by Kaplan-Meier analysis. A/B, n=6; C/D n=12.

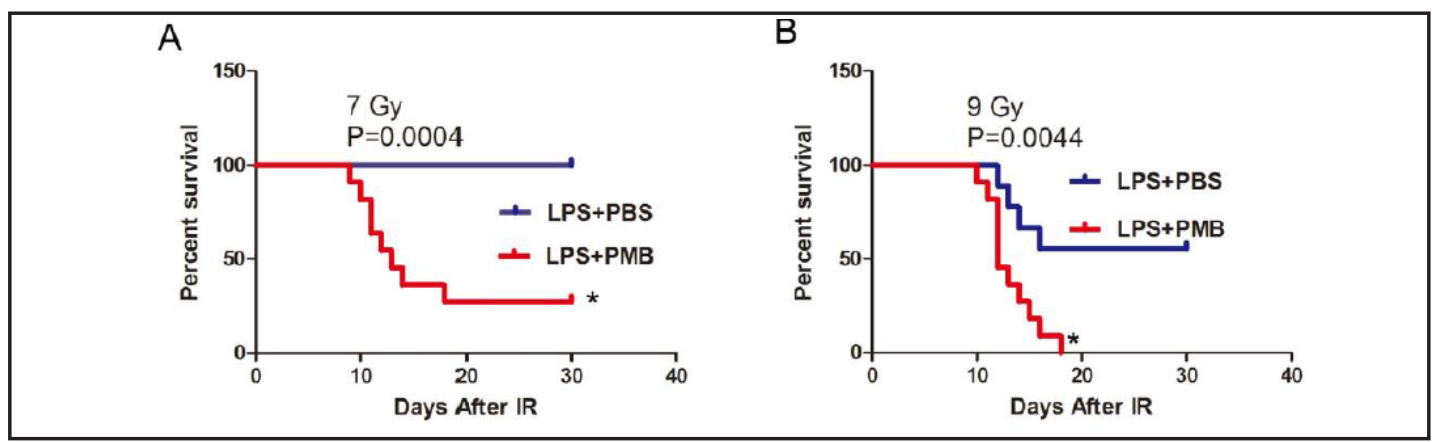

Fig. 2. PMB decreased the LPS-induced radioprotective effect. Mice were pretreated with PMB (100 $\mu \mathrm{g} /$ mouse, $n=24$ mice) for30 minutes and then treated with LPS ( $(50 \mu \mathrm{g} /$ mouse, $\mathrm{n}=24 \mathrm{mice})$. Mice that only received LPS were regarded as control. Then, these mice received radiation ( 7 and $9 \mathrm{~Gy}, \mathrm{n}=12$ mice for each dose). The survival status of the mice was recorded daily. The differences in survival between the two groups of mice were evaluated by Kaplan-Meier analysis (A/B).

these data confirmed that PMB is an inhibitor of LPS-induced TLR4 signaling, and additionally PMB exacerbated radiation-induced death.

\section{PMB blocked the LPS induced radioprotection effect.}

PMB could exacerbate radiation effects and LPS could induce radioprotection. Accordingly, we next investigated whether PMB could reduce the radioprotective effect of LPS. Mice were pretreated with PMB ( $1 \mu \mathrm{g} /$ mouse) and LPS (50 $\mu \mathrm{g} /$ mouse) for 24 hours.

\section{KARGER}



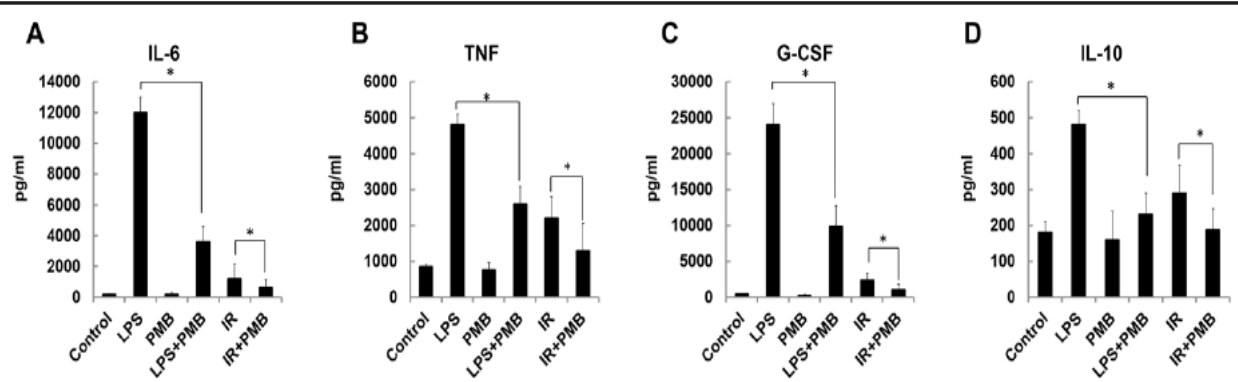

Fig. 3. PMB reduced IL-6, TNF- $\alpha$, G-CSF and IL-10 levels induced by LPS/IR in vivo. 30 mice were pretreated with PMB (100 $\mu \mathrm{g} /$ mouse) for 30 minutes. Afterwards, 10 mice received LPS and 4 hours later, all mice were euthanized for the analysis of IL-6, G-CSF , TNF- $\alpha$ and IL-10 level in serum (ABC). The experiments were performed in triplicate. Data are represented as the mean \pm s.d. ${ }^{*} P<0.05$ (Con group: control group).

Fig. 4. The survival rates of WT, Myd88\%, IL$6 \%$, TLR $4 \%$ mice and PMB-treated mice. First, wild type mice were pretreated with or without PMB for 30 minutes. Next, the PMB pretreated mice, Myd88\%, IL- $6 \%$ and TLR4 $\%$ mice each received either LPS ( $1 \mathrm{mg} / \mathrm{mouse}$ ) or radiation ( 9 Gy), and the survival status of the mice were recorded. The differences in survival between the two groups of mice were evaluated by Kaplan-Meier analysis (A/B).

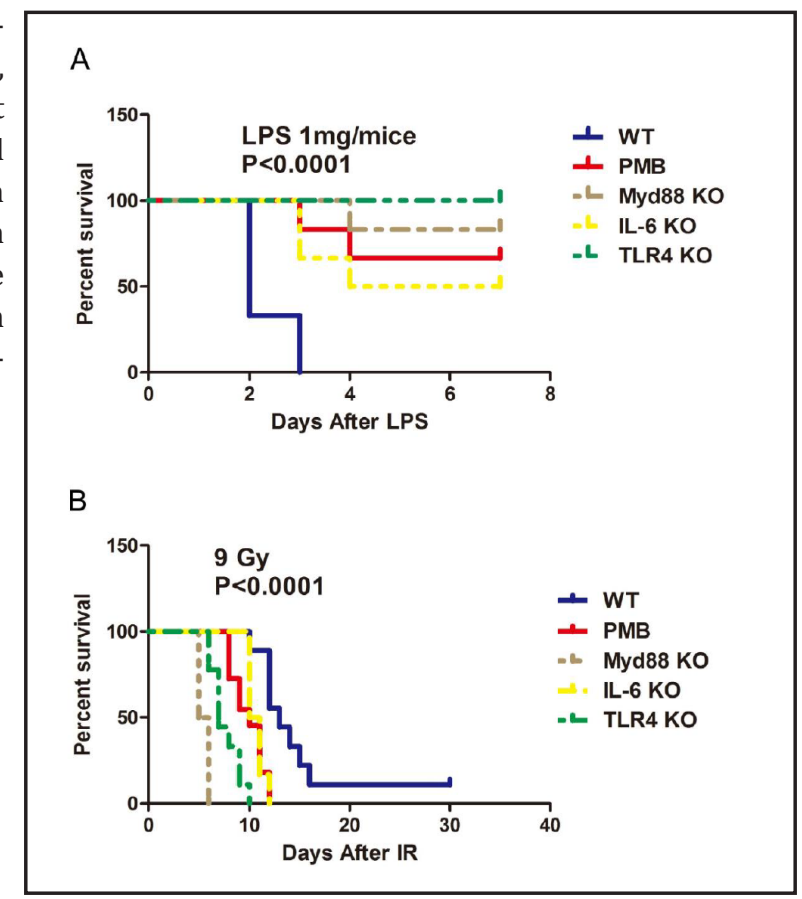

Subsequently these mice received radiation (7 and 9 Gy) and the survival status of the mice was recorded daily. We found that PMB blocked the LPS induced radioprotective effect (Fig. 2A/B).

PMB reduced IL-6, TNF- $\alpha, G-C S F$ and IL-10 levels induced by LPS/IR in vivo.

IL-6 and G-CSF were shown to be radiation protection factors [22, 23]. TNF- $\alpha$ and IL-6 were the main cytokines induced by LPS $[24,25]$. And IL-10 was typical anti-inflammatory interleukins. Thus, to investigate the involved mechanism of PMB decreasing LPS induced mice mortalities, we tested the IL-6, TNF- $\alpha$, G-CSF and IL-10 in the serum of mice pretreated with LPS, PMB , LPS combined PMB, with or without PMB before total-body radiation(7Gy). and we found that LPS promoted the IL-6, TNF- $\alpha$, G-CSF and IL-10 levels in the serum of mice following $24 \mathrm{~h}$ stimulation. In mice pretreated with LPS combined PMB, we found that PMB decreased the IL-6, TNF- $\alpha$, G-CSF and IL-10 levels in the serum induced by LPS. And PMB also reduced the serum levels of interleukins (IL-6, TNF, G-CSF and IL-10) of radiationtreated mice, but the difference is not as sharp as the LPS model. (Fig. 3A/B/C/D). 
Fig. 5. Possible mechanism for PMB in different regulation of LPS-induced death and radiation induced death (MOF: multiple organ failure).

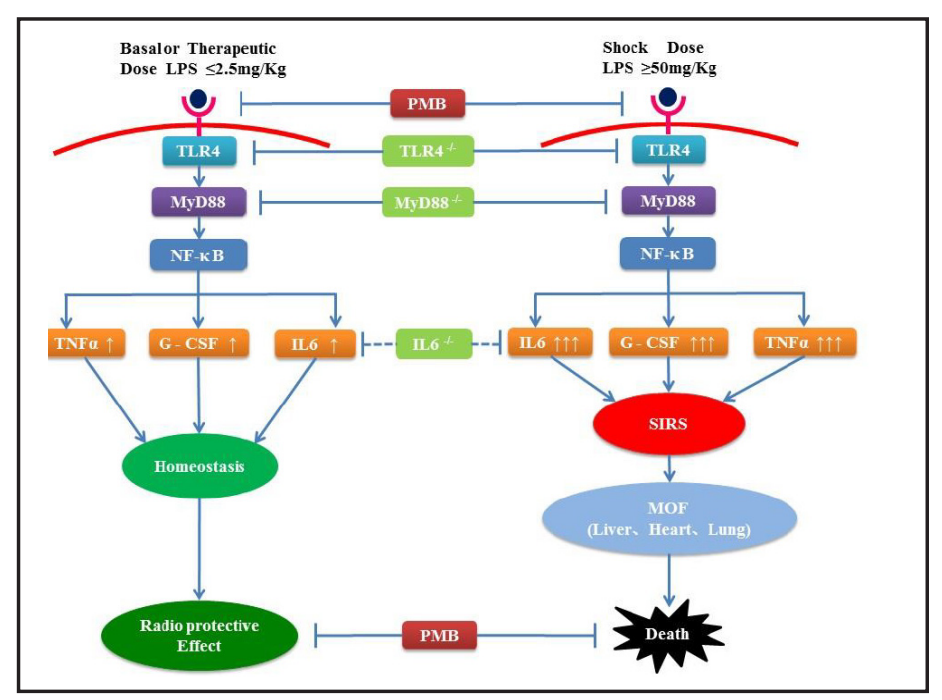

TLR4 -/- , Myd88-/- and IL-6-/- mice mimic the effect of PMB in different regulation of LPS induced death and radiation induced mortalities

Our previous study showed that IL-6\% mice were more resistant to LPS-induced death but less resistant to radiation-induced death than wild type mice [19]. Accordingly, in this study, Myd88\%, IL-6\% and TLR4\% mice were used to test the role of PMB in LPS-induced and radiation-induced mortality in mice. Wild type mice were pretreated with PMB for 24 hours. Next, the PMB pretreated mice, Myd88\%, IL-6\% and TLR4\% mice separately received LPS ( $1 \mathrm{mg} /$ mouse) and radiation ( $9 \mathrm{~Gy}$ ), and the survival status of the mice was recorded. We found that the Myd88, IL-6, TLR4 knockout mice and the PMB pretreated mice had higher survival rates than the wild type mice in the LPS treated groups (Fig. 4A); on the contrary, Myd88, IL-6, TLR4 knockout mice and PMB pretreated mice showed lower survival rates than wild type mice in radiation treated groups (Fig. 4B). Additionally, our data revealed that the effect of PMB stimulation is similar to the effect of knocking out Myd88, IL-6 and TLR4. Thus, we inferred that PMB may play its role via the TLR4-Myd88-IL-6 pathway.

\section{Discussion}

To the best of our knowledge, this is the first report on the role of PMB in different regulation of radiation effects. We found that PMB exacerbated radiation-induced death but aggravates radiation-induced death in vivo. In addition, a study of the molecular mechanism in gene knockout mice and data indicated that the TLR4-Myd88-IL-6 pathway may play a key role in mediating the PMB effects.

It is known that the TLR4-Myd88-IL-6 pathway plays very different roles in LPSinduced systemic inflammatory response syndrome (SIRS) and radiation exposure [26-31]. In addition, LPS from Gram-negative bacteria is one of the most potent innate immuneactivating stimuli. LPS-inducible cytokines included TNF- $\alpha$, IL-1 family, IL-6, IL-8, IL-10 family, the IL-12 family, IL-15, TGF- $\beta$ and G-CSF [17, 30, 32-35]. And those hyperreactive inflammatory responses caused by LPS killed pretreated mice. Our results showed that mice pretreated with PMB had higher survival rates than the wild type mice in the LPS treated groups, and TLR4 -/-, Myd88-/- and IL-6-/- mice mimic the effect of PMB in regulation of LPS induced death. So we concluded that Polymyxin B may attenuates LPS-induced death via TLR4-Myd88-IL-6 pathway.

In our previous study [9], exposure to radiation led to significant endotoxemia that also confers endogenous protection against radiation. The circulating endotoxins appear to originate from the gut. Moreover, we also proved that TLR4 play a critical role in basal radioresistance, and TLR4-/- mice were more susceptible to radiation-induced death. In this study, we found that PMB increased the radiation-induced mortality in mice, while gene knock- 


\section{Cellular Physiology Cell Physiol Biochem 2017;42:1120-1126 \begin{tabular}{ll|l} 
DOI: 10.1159/000478767 217 & $\begin{array}{l}\text { O 2017 The Author(s). Published by S. Karger AG, Basel } \\
\text { www.karger.com/cpb }\end{array}$
\end{tabular}}

Cheng et al.: Polymyxin B Aggravates Radiation-Induced Death via TLR4

out mice mimic the effect of PMB in regulation of radiation induced mortalities. Therefore, we hypothesized that PMB may increase the radiation-induced mortality by disrupting the TLR4 signaling pathway.

Furthermore, we also found that PMB reduced the LPS-induced levels of IL-6, G-CSF, IL-10 and TNF- $\alpha$ in vivo. IL- 6 and G-CSF are known radiation protection factors. TNF- $\alpha$ is the main factor released in endotoxemia [25, 36]. And IL-10 was typical anti-inflammatory interleukins. Thus, we concluded that mechanism whereby PMB exacerbates radiationinduced death involves the disruption of the production of cytokines (Fig. 5).

In conclusion, our data revealed the role of PMB in LPS treatment and radiation treatment, and the TLR4-Myd88-IL-6 pathway plays important roles by disturbing the production of cytokines.

\section{Acknowledgments}

This study was supported by the grant from National Natural Science Foundation of China (No. 8157120903).

\section{Disclosure Statement}

The authors declare no conflict of interest.

\section{Reference}

1 Akira S: Toll-like receptors and innate immunity. Adv Immunol 2001;78:1-56.

2 Kawai T, Akira S: The role of pattern-recognition receptors in innate immunity: update on Toll-like receptors. Nat Immunol 2010;11:373-384.

- 3 Kumar H, Kawai T, Akira S: Toll-like receptors and innate immunity. Biochem Biophys Res Commun 2009;388:621-625.

Medzhitov R: Toll-like receptors and innate immunity. Nat Rev Immunol 2001;1:135-145.

Takeda K, Akira S: Toll-like receptors in innate immunity. Int Immunol 2005;17:1-14.

Uematsu S, Akira S: Toll-like receptors and innate immunity. J Mol Med (Berl) 2006;84:712-725.

Banerjee A, Gerondakis S: Coordinating TLR-activated signaling pathways in cells of the immune system. Immunol Cell Biol 2007;85:420-424.

8 Gao F, Zhang C, Zhou C, Sun W, Liu X, Zhang P, Han J, Xian L, Bai D, Liu H, Cheng Y, Li B, Cui J, Cai J, Liu C: A critical role of toll-like receptor 2 (TLR2) and its' in vivo ligands in radio-resistance. Sci Rep 2015;5:13004.

-9 Liu C, Zhang C, Mitchel RE, Cui J, Lin J, Yang Y, Liu X, Cai J: A critical role of toll-like receptor 4 (TLR4) and its' in vivo ligands in basal radio-resistance. Cell Death Dis 2013;4:e649.

-10 Cruz DN, Antonelli M, Fumagalli R, Foltran F, Brienza N, Donati A, Malcangi V, Petrini F, Volta G, Pallavicini FMB: Early use of polymyxin B hemoperfusion in abdominal septic shock: the EUPHAS randomized controlled trial. Jama 2009;301:2445-2452.

-11 Evans ME, Feola DJ, Rapp RP: Polymyxin B sulfate and colistin: old antibiotics for emerging multiresistant gram-negative bacteria. Ann Pharmacother 1999;33:960-967.

12 Gales AC, Reis AO, Jones RN: Contemporary assessment of antimicrobial susceptibility testing methods for polymyxin B and colistin: review of available interpretative criteria and quality control guidelines. J Clin Microbiol 2001;39:183-190.

13 McPhee JB, Lewenza S, Hancock RE: Cationic antimicrobial peptides activate a two-component regulatory system, PmrA-PmrB, that regulates resistance to polymyxin B and cationic antimicrobial peptides in Pseudomonas aeruginosa. Mol Microbiol 2003;50:205-217.

14 Yoon J, Urban C, Terzian C, Mariano N, Rahal JJ: In vitro double and triple synergistic activities of Polymyxin $\mathrm{B}$, imipenem, and rifampin against multidrug-resistant Acinetobacter baumannii. Antimicrob Agents Chemother 2004;48:753-757. 


\section{Cellular Physiology Cell Physiol Biochem 2017;42:1120-1126 \begin{tabular}{l|l} 
and Biochemistry & $\begin{array}{l}\text { DOI: 10.1159/000478767, } \\
\text { Published } 2017 \text { The Author(s). Published by S. Karger AG, Basel }\end{array}$ \\
\hline www.karger.com/cpb
\end{tabular}

15 Palmer JD, Rifkind D: Neutralization of the hemodynamic effects of endotoxin by polymyxin B. Surg Gynecol Obstet 1974;138:755-759.

16 Lindemann RA: Bacterial activation of human natural killer cells: role of cell surface lipopolysaccharide. Infect Immun 1988;56:1301-1308.

17 Han C, Ding Z, Shi H, Qian W, Hou X, Lin R: The Role of Probiotics in Lipopolysaccharide-Induced Autophagy in Intestinal Epithelial Cells. Cell Physiol Biochem 2016;38:2464-2478.

$\checkmark 18$ Duff GW, Atkins E: The inhibitory effect of polymyxin B on endotoxin-induced endogenous pyrogen production. J Immunol Methods 1982;52:333-340.

-19 Li B, Zhang C, He F, Liu W, Yang Y, Liu H, Liu X, Wang J, Zhang L, Deng B, Gao F, Cui J, Liu C, Cai J: GSK-3beta inhibition attenuates LPS-induced death but aggravates radiation-induced death via down-regulation of IL-6. Cell Physiol Biochem 2013;32:1720-1728.

20 Yang Y, Li B, Liu C, Chuai Y, Lei J, Gao F, Cui J, Sun D, Cheng Y, Zhou C, Cai J: Hydrogen-rich saline protects immunocytes from radiation-induced apoptosis. Med Sci Monit 2012;18:Br144-148.

21 Liu C, Gao F, Li B, Mitchel RE, Liu X, Lin J, Zhao L, Cai J: TLR4 knockout protects mice from radiationinduced thymic lymphoma by downregulation of IL6 and miR-21. Leukemia 2011;25:1516-1519.

-22 Patchen ML, Fischer R, MacVittie TJ: Effects of combined administration of interleukin- 6 and granulocyte colony-stimulating factor on recovery from radiation-induced hemopoietic aplasia. Exp Hematol 1993;21:338-344.

23 Krivokrysenko VI, Shakhov AN, Singh VK, Bone F, Kononov Y, Shyshynova I, Cheney A, Maitra RK, Purmal A, Whitnall MH, Gudkov AV, Feinstein E: Identification of granulocyte colony-stimulating factor and interleukin- 6 as candidate biomarkers of CBLB502 efficacy as a medical radiation countermeasure. J Pharmacol Exp Ther 2012;343:497-508.

24 Dumitru CD, Ceci JD, Tsatsanis C, Kontoyiannis D, Stamatakis K, Lin JH, Patriotis C, Jenkins NA, Copeland NG, Kollias G, Tsichlis PN: TNF-alpha induction by LPS is regulated posttranscriptionally via a Tpl2/ERKdependent pathway. Cell 2000;103:1071-1083.

-25 Fehr S, Unger A, Schaeffeler E, Herrmann S, Laufer S, Schwab M, Albrecht W: Impact of p38 MAP Kinase Inhibitors on LPS-Induced Release of TNF-alpha in Whole Blood and Primary Cells from Different Species. Cell Physiol Biochem 2015;36:2237-2249.

26 Johnson GB, Brunn GJ, Platt JL: Cutting edge: an endogenous pathway to systemic inflammatory response syndrome (SIRS)-like reactions through Toll-like receptor 4. J Immunol 2004;172:20-24.

27 Child NJ, Yang IA, Pulletz MC, de Courcy-Golder K, Andrews AL, Pappachan VJ, Holloway JW: Polymorphisms in Toll-like receptor 4 and the systemic inflammatory response syndrome. Biochem Soc Trans 2003;31:652-653.

28 Matsuda N, Hattori Y: Systemic inflammatory response syndrome (SIRS): molecular pathophysiology and gene therapy. J Pharmacol Sci 2006;101:189-198.

29 Kaukonen KM, Bailey M, Pilcher D, Cooper DJ, Bellomo R: Systemic inflammatory response syndrome criteria in defining severe sepsis. N Engl J Med 2015;372:1629-1638.

- 30 Yin X, Liang Z, Yun Y, Pei L: Intravenous Transplantation of BMP2-Transduced Endothelial Progenitor Cells Attenuates Lipopolysaccharide-Induced Acute Lung Injury in Rats. Cell Physiol Biochem 2015;35:21492158.

-31 Zhang X, Dong H, Zhang S, Lu S, Sun J, Qian Y: Enhancement of LPS-induced microglial inflammation response via TLR4 under high glucose conditions. Cell Physiol Biochem 2015;35:1571-1581.

-32 Rossol M, Heine H, Meusch U, Quandt D, Klein C, Sweet MJ, Hauschildt S: LPS-induced cytokine production in human monocytes and macrophages. Crit Rev Immunol 2011;31:379-446.

-33 Grunfeld C, Zhao C, Fuller J, Pollack A, Moser A, Friedman J, Feingold KR: Endotoxin and cytokines induce expression of leptin, the ob gene product, in hamsters. J Clin Invest 1996;97:2152-2157.

-34 Matsuguchi T, Musikacharoen T, Ogawa T, Yoshikai Y: Gene expressions of Toll-like receptor 2, but not Toll-like receptor 4 , is induced by LPS and inflammatory cytokines in mouse macrophages. J Immunol 2000;165:5767-5772.

-35 de Waal Malefyt R, Abrams J, Bennett B, Figdor CG, de Vries JE: Interleukin 10(IL-10) inhibits cytokine synthesis by human monocytes: an autoregulatory role of IL-10 produced by monocytes. J Exp Med 1991;174:1209-1220.

-36 Bouchama A, Parhar RS, el-Yazigi A, Sheth K, al-Sedairy S: Endotoxemia and release of tumor necrosis factor and interleukin 1 alpha in acute heatstroke. J Appl Physiol (1985) 1991;70:2640-2644. 